Letras, Lima 48 (82-83): 11-31, 1976.

\title{
La filosofía y la ciencia
}

GUSTAVO SACO

La historia de la filosofía nos enseña que la cuestión primordial de la disciplina filosófica es la concerniente a la naturaleza del ser. Esa misma historia revela que para responder a la cuestión primordial del ser, la respuesta materialista y la respuesta espiritualista son las únicas que se disputan el derecho a representar a la verdad definitiva. A su vez, acerca de la naturaleza material o espiritual del ser, los filósofos, en el transcurso de la historia, solamente han hallado, por un lado, la posición monista materialista, o la posición monista espiritualista y, por otro lado, la posición dualista que acepta que subsisten dos entes, el uno materia y el otro espíritu que de algún modo se interrelacionan, pero que en lo substancial son de una naturaleza irreductible. Es cierto también que los intentos de solúción dualista dados por los filósofos en diversas' épocas, ihan iconducido en última instancia a una posición monista espiritualista, porque ante la presión de las interrogantes, el dualismo ha concluido que la materia tiene su razón de existir en una fuerza espiritual que se refleja en las tendencias del comportamiento material mismo, y por lo tanto, el análisis de la materia constataría que su ser obedece fundamentalmente a principios espirituales. El monismo materialista es representado por la filosofía materialista que solamente acepta la existencia de la materia, la cual tiene su razón de existir en sí mis$\mathrm{ma}$, sin que haya ningún otro factor que la haya originado y el universo lo constituye únicamente el universo físico. El monismo espiritualista está representado por el llamado idealismo objetivo, el cual considera que solamente existe el espíritu, en tanto que la materia no es sino la forma aparente en que se realiza el espíritu. El universo es exclusivamente espíritu, tiene su razón de ser en sí mismo, ajeno a la intervención de otro factor.

El dualismo, sostiene la existencia de la materia, por un lado, y del espíritu, por otro lado. Pero ni la materia puede espiritualizarse, ni el espíritu materializarse. La materia no tiene su 
razón de existir en sí misma, pues sólo la intervención de un factor espiritual ha hecho posible su existencia. Subsisten dos mundos o universos, el mundo físico y el mundo espiritual, pero en tanto que el mundo del espíritu tiene su razón de ser en sí, el mundo material, en cambio, requiere del espíritu para existir. En el dualismo, aun cuando la materia y el espíritu subsisten, la prioridad está reservada al espíritu, por cuanto, en última instancia, la materia se rige por principios espirituales, pero el espíritu no se rige por ningún principio material. Esta dualidad de materia y espíritu se patentiza en el hombre. Como de hecho, para el dualismo, el espíritu y la materia se correlacionon, se ha elaborado diversos intentos para explicar cómo se lleva a cabo esa relación y la respuesta es de que, tratándose del mundo o universo en general, la relación se efectúa por un acto de creación; y en lo que respecta a la relación del espíritu y cuerpo del hombre, en lo fundamental se refieren a que el hombre así ha sido creado, pues para el dualismo, la relación no tiene propiamente explicación, en el sentido de una interrelación, y se limita a establecer alguna forma de paralelismo, o mejor dicho, a constatar alguna forma de paralelismo. Es a este paralelismo al cual se le podría denominar explicación en la posición dualista. En su forma más consecuente, el dualismo sostiene que de algún modo el espíritu del hombre ejerce una acción sobre su aspecto corporal, pero sin llegar a precisar el proceso íntimo mediante el cual se lleva a cabo esa acción. Propiamente, la posición dualista no considera el paralelismo como la única forma de establecer la relación entre el espíritu y cuerpo.

Al lado de la posición monista materialista, o espiritualista, - la posición dưalista,Ploscifíósớfos lhan'sintentado también una cuarta posición, en tanto que la materia y el espíritu -extensión y pensamiento- son dos atributos de un ser divino, como lo expresa el panteísmo. Como es evidente, esta filosofía se reduce finalmente a una concepción espiritualista del ser, que bien podría asemejarse a una forma del idealismo objetivo. Por otro lado, el intento de considerar como derivados de una misma substancia, la extensión y el pensamiento ha sido interpretado por algunos materialistas como una forma del materialismo. De todos modos, la posición panteísta tal como lo enseña la historia de la filosofía, no escapa a las únicas dos alternativas, o el ser es materia o espíritu.

La cuestión fundamental de la filosofía: ¿Qué es el ser?, ha tenido únicamente dos respuestas categóricas, o el ser es materia, o el ser es espíritu, y la historia de la filosofía comprueba que los filósofos han aducido argumentos para defender en última instancia, una u otra alternativa. Empero, los filósofos no se han encontrado solos en los esfuerzos para responder a la cuestión fundamental, como así lo constata la historia de la ciencia, 
pues los científicos al abordor el estudio de la naturaleza inanimada o animada, al descubrir las leyes que la rigen, han permitido deslindar con más precisión las causas materiales que promueven el comportamiento de los seres inanimados o animados. Esta misma historia de la ciencia nos enseña que muchas manifestaciones de la naturaleza, que anteriormente fueron interpretadas como expresión de fuerzas espirituales, han tenido. que ser replanteadas con ocasión de las leyes materiales que han sido descubiertas.

Desde el crudo pensamiento animista de épocas remotas o del presente en algunas de nuestras culturas, hasta el descubrimiento de leyes materialistas que rigen el mundo físico, biológico y humano, como lo ha ido estableciendo la ciencia hasta llegar a la actualidad, se ha visto retroceder la interpretación espiritualista. De todos modos, la ciencia ha llevado a cabo una tarea de considerables proporciones para zanjar las cuestiones de si el ser de la naturaleza cmimada o inanimada es material o espiritual. De aquí que es legítimo afirmar que sin el aporte de la ciencia, la cuestión filosófica fundamental acerca de la substancia material o espiritual del ser, no hubiese avanzado al paso que lo ha logrado por el camino de la ciencia. El rigor de los procedimientos científicos es el único que permitirá escudriñar la naturaleza y esperar una respuesta cada vez más precisa acerca de la verdadera substancia del ser. Sin embargo, lo dicho anteriormente no implica que la ciencia haya dado una respuesta definitiva a la cuestión fundamental, pues sería como pedirle que haya resuelto ya todos los problemas concernientes a la naturaleza del universo. En todos los casos, es posible afirmar, con la historia de la ciencia, que su aporte ha sido extremadamente considerable para acercarse a la solución de este problema filosófico primordial. Pretender resolver algún problema filosófico, desconóciendo o pretendiendo ignorar las contribuciones que la ciencia haya dado en torno de un problema, sería como darle las espaldas a una realidad descubierta con afón y riqueza por la ciencia. Aún más, la misma historia de la filosofía enseña que cuando floreció la ciencia, las grandes cuestiones filosóficas estuvieron, de un modo $u$ otro, ligadas al pensamiento científico.

La correlación entre la filosofía y la ciencia es tom antigua como los orígenes de la ciencia, pues a partir de ese momento, filosofía y ciencia han marchado profundamente unidas. La influencia que ha tenido la ciencia sobre la filosofía, tanto en los filósofos materialistas como en los filósofos idealistas, es evidente, pues en todos los tiempos los filósofos al considerar los datos de la ciencia han derivado sus consecuencias materialistas o idealistas. Algunos de los fundamentos idealistas de la filosofía platónica se derivan en parte de su conocimiento del desarrollo del pensamiento geométrico; la dialéctica idealista hegeliana requirió. de 
una buena dosis de conocimientos científicos; e igualmente algunos filósofos idealistas contemporáneos como Whithead elaboran su filosofía tomando en todo momento en consideración, el desenvolvimiento de la ciencia. Con mayor argumentación, los filósofos materialistas han utilizado y utilizan los datos de las ciencias naturales para afianzar su posición materialista, fuera del hecho de que para muchos, las aportaciones de las ciencias de la naturaleza los inclinan a una posición materialista en la filosofía. Ya sea para identificar la filosofía con el materialismo, o ya sea para contraponer el materialismo con el idealismo, es el hecho de que el filósofo tiene que tomar en consideración el tremendo desarrollo del pensamiento científico, el cual en todo caso, nos da a conocer una parte de la realidad, para afianzarse en sus posiciones materialistas o idealistas. Ejemplos eminentes en la historia de la filosofía son Aristóteles, Descartes, Kant, Bertrand Russell, quienes en todo momento tomaron en consideración los conocimientos de las diversas ciencias de su época para concluir en una filosofía materialista o idealista. La filosofía pudo estar desligada de la ciencia cuando no hubo ciencia, pero desde el momento de la aparición de ésta ultima no ha logrado desligarse de ella y por el contrario son mayores los vínculos cuanto más extenso es el desarrolio científico. A medida que se desarrollan las ciencias humanas con la sociología y la psicología, el filósofo tiene que meditar sobre los aportes de estas ciencias, como se revela en la creciente expansión de la filosofía de las ciencias psicológicas y sociales que recurren incesantemente a las disciplinas correspondientes de estas ciencias. Es una consecuencia inevitable que al tener la filosofía como uno de sus problemas fundamentales, el estudiorde la readiddd, tenga lque tomar en consideración lo que la ciencia aporta sobre la realidad; si es otro de sus problemas fundamentales el problema del conocimiento, tenga que tomar en cuenta lo que las ciencias aporten sobre la gestación del conocimiento, como lo hace la psicología, las ciencias sociales, la fisiología y biología y las mismas ciencias matemáticas; y si es su tercer problema fundamental el problema de los valores y la moral, debe de meditar sobre lo que nos enseñan las ciencias sociales sobre la variedad de valores que ha habido en la historia de las sociedades, y los diversos criterios que sobre el bien y el mal se ha desarrollado en ellas. En las conexiones que se establece entre la filosofía y la ciencia precisa distinguir en qué nivel se revela el pensamiento completamente científico y en qué nivel se revela un pensamiento genuinamente filosófico. La observación de los hechos concretos de la naturaleza o sociedad, el acarreamiento de los datos, el establecimiento de correlaciones entre los hechos, la formulación causal y el establecimiento de leyes corresponden a una actividad propia de la ciencia. Mas, como toda ciencia tiene sus propias categorías como por ejemplo el número, la can- 
tidad, el espacio, el tiempo, la vida, la evolución, la relación del cuerpo y la mente, la conciencia, el devenir histórico y social, categorías que son de interés primordial para el teórico de la ciencia, pero que también son de interés primordial y han sido siempre preocupación constante de la filosofía, estas categorías son también de la filosofía. En este nivel el científico teórico y el filósofo llevan a cabo una actividad común por lo cual sus tareas se confunden, analizan un mismo problema y buscan sus soluciones. Esto significa que el científico que aborda el estudio de estos problemas, paulatinamente se convierte en un filósofo, y lo que es equivalente, el filósofo que los aborda se confunde con el científico teórico y de aquí que los científicos al abordar estas categorías son justamente llamados científicos y filósofos y de aquí la proclividad de los teóricos de la ciencia en interesarse en los problemas filosóficos. Así, el científico al plantear cuestiones fundamentales sobre el espacio y el tiempo, por ejemplo, en la teoría de la relatividad, es un científico, que se convierte en un filósofo y científico, al plantear problemas de perenne interés para la filosofía; la teoría de la evolución, ha sido igualmente de interés para el pensamiento filosófico, e igualmente acontece con otras categorías comunes a la ciencia y a la filosofía. A partir de este nivel desaparece la comunidad de intereses del científico y del filósofo o, mejor dicho, entre la ciencia y la filosofía, pues a un tercer nivel, el más elevado de los tres, el interés se vierte en la consideración de las categorías del ser, esto es, en la consideración de las características universales de los procesos del mundo, asunto que es de genuino interés filosófico y quienquiera que ascienda a este nivel no actúa ya, ní como científico, ni como teórico de la ciencia, yosígcomo un filósofo genuino, como un indagador de un problema propio de la filosofía. Desde este nivel su visión filosófica debe abarcar lo que es común y diferencial del ser físico, biológico, psicológico y social, o de cualquier otro ser que el filósofo pretenda que hay en el mundo. Mas, que sea un nivel propio de la filosofía no excluye sino que, al contrario, requiere que la solución que se dé a los problemas que plantean las categorías universales de la filosofía, tomen en cuenta lo que han aportado todas las ciencias, y muy especialmente, lo que ha aportado la teoría de la ciencia. Así, por ejemplo, si vamos a atribuir al ser la libertad o la causalidad, debemos considerar lo que la ciencia ha aportado sobre este problema en el ser físico, biológico, psicológico, y social. Pues sería un absurdo si la filosofía concluyese que el ser es determinado o que no es determinado, si algunas de las manifestaciones del ser en los campos mencionados no revelasen las características que le atribuye la filosofía, por cuanto, como seres, deben poseer o no las características atribuidas. Si no hay concordancia entre la filosofía y la ciencia, hay que reajustar las interpretaciones científicas, o las 
conclusiones filosóficas. En lo referente a la teoría general del ser, lo que la ciencia concluya sobre la naturaleza de los fenómenos físicos, sobre la constitución de la materia, sobre su estructura, por ejemplo, tiene que influenciar sobre las concepciones filosóficas acerca del ser. Si la materia misma no está sujeta a la causalidad, si el indeterminismo es lo propio del mundo físico, como sostienen algunos filósofos, quedaría excluido definitivamente de las categorías del ser la determinación, y el ser será indeterminado. Pero si, en cambio, quedase demostrado de que el mundo físico está rigurosamente determinado por la causalidad, no se podría considerar la categoría de indeterminación como adecuada al ser en general y habría, más bien, que restringirla, por de pronto, a otras esferas, dejando al mismo tiempo, en la problemática filosófica, el establecer si otras esferas del ser no podrían también estar rigurosamente determinados por la causalidad. Consideraciones análogas pueden hacerse en la repercusión que tenga la ciencia sobre la teoría general del ser, al analizar las categorías que han de regir en los fenómenos biológicos, o en los procesos psicológicos y sociales. Ásí, la misma categoría del determinismo $\circ$ indeterminismo puede indagarse si es o no aplicable a lo psíquico, a lo social o a lo biológico. Sobre la relación del cuerpo y el espíritu, este primordial y perenne problema de la filosofía, sólo puede encontrar una respuesta definitiva por intermedio de la ciencia. Si el ser es únicamente material, o únicamente espiritual, o si subsisten los dos irreconciliablemente, uno al lado del otro, sólo la ciencia física en comparación con la ciencia psicológica, podrá establecer al estudiar las diversas categorías que rigen en lo físico y en lo psíquico, si hay unidad entre ellas, o si hay discrepancias esencialesicpudieñdolsólósentonces precisar cómo es posible que lo uno y lo otro se vinculen, y si hay unidad entre ellos, donde hay que indagar sobre la correlación que en todo caso se observa entre lo físico y lo psíquico. Iguales consideraciones pueden hacerse acerca de la relación de lo físico y lo biológico.

En el campo axiológico, si una forma de representación es más valiosa que otra, si el realismo es de más valor que el subjetivismo, o inversamente, si estas dos formas de representación poseen una misma cualidad valorativa, implica tomar en cuenta el acontecimiento social e histórico, los factores que originaron una u otra forma de representación artística, y evaluar críticamente el arte que ellas representan. La teoría axiológica insurge precisamente, ante el hecho de que tanto en los pueblos como en los individuos hay diversas realizaciones y apreciaciones del arte. De igual modo en lo referente al bien y al mal, surge la teoría de la moral. El acontecimiento social e histórico al revelar diversas formas artísticas y formas de comportamiento ético, no solamente estimula la crítica sino que, fundamentalmente, comprue- 
ba ante los hechos históricos y sociales, cuáles son los modos de actuar del hombre que son favorables o desfavorables para su desarrollo y superación integrales. La historia y el comportamiento de la sociedad es la forma viva de realización del valor y del bien, o del antivalor o del mal. Es indiscutible que dentro de la variedad y contraposición del acontecer humano, es posible extraer lo que es beneficioso para la vida del hombre, pero esta conclusión no es extraída únicamente a priori sino que está basada en una experiencia que a posteriori contribuye intensamente a fundamentar lo valioso y lo bueno, a demostrar cuáles son las formas de vida humana que lo hacen posible. Es evidente que siempre queda en pie la cuestión de cual sea la base definitiva para caracterizar lo valioso o lo bueno, para lo cual no es suficiente el acontecer humano sino que requiere una visión total del cosmos y de la naturaleza humana en particular, para lo cual es necesario un nivel de elevación general y universal que sitúa al problema en un plano genuinamente filosófico, pero que en ningún momento puede desconocer las posibilidades del mundo en su origen y desarrollo, para lo cual los hechos y las leyes de la ciencia dan su contribución.

La teoría de los valores es marcadamente afectada por el de. sarrollo de las ciencias sociales, pues el estudio comparativo de diversos grupos étnicos permite constatar que diversos pueblos tienen normas acerca del bien que son completamente opuestas, de donde se desprende la interrogante de cuál de ellas es la que conduce debidamente por el bien mismo. En todo caso, el estudio social comparado deståca cuán compenētrados están los va'ores con las condiciones sociales existentes, lo cual nadie puede negar si estudia pueblos en estadios de desarfollb llamados primitivos, pero que al mismo tiempo invita a reflexionar, si las llamadas sociedades civilizadas, en sus normas de bien, no están profundamente influenciadas por las condiciones sociales imperantes, y si las mismas teorías filosóficas sobre el valor, no son una pura reflexión sobre ese tema, sino que también están influenciadas por las mismas condiciones sociales. Se plantea entonces la pregunta: ¿Es el valor algo que tiene vigencia por sí mismo o que depende de la vida social? En el caso de que tuviera vigencia por sí mismo, de todos modos las ciencias sociales ayudarán a depurar las teorías filosóficas sobre el valor, de todo contenido que extrañamente se hubiese compenetrado con ellas. $\mathrm{Si}$ de lo contrario, las ciencias sociales establecen que en todos los casos, las normas de conducta son sólo parte integrante de la vida social, habría que hacer descender la teoría de los valores del mundo ultrasensible al mundo de la vida social. ¿O es acaso la captación del bien en relación social una vivencia que se sustenta en el valor mismo y que después se aplica a la vida social, haciéndose norma de conducta que se consolida a través de gene- 
raciones para el desonvolvimiento social, y que para un estudioso de las ciencias sociales le parecen depender exclusivamente de las condiciones sociales existentes? Cabría entonces una tercera posibilidad, a saber, de que el valor tenga vigencia por sí mismo, pero que determinadas situaciones históricas permiten la realización de una parte de él, o dificulten su comprensión, o que sea utilizado por la sociedad con el propósito de satisfacer ciertas necesidades inmediatas. Queda entonces el problema: ¿Cuál es la relación entre la sociedad y valor? A su esclarecimiento han de contribuir fundamentalmente las ciencias sociales. En lo concerniente a la teoría ética de la libertad, las ciencias psicológicas están también llamadas a contribuir a dar una respuesta definitiva, precisando los límites en que la psiquis está determinada causalmente, o si queda un margen de libertad al espíritu, o si definitivamente el hombre está determinado en todas sus formas de comportamiento. Las ciencias psicológicas habrán de concluir cómo opera la causalidad en el psiquismo humano, siguiendo detenidamente, a base de un conocimiento científico, dentro de qué ámbito actúa la causalidad. La teoría ética sobre la libertad deberá su validez, o su esfera de validez, a lo que concluyan las ciencias psicológicas, en lo que respecta a la aplicación o no de la causalidad en el espíritu humano.

En el campo del conocimiento, la filosofía que se ocupa de esta disciplina tiene que tomar en consideración en el problema de la percepción, por ejemplo, la anatomía y la fisiología de los órganos de los sentidos, del sistema nervioso y en particular de los centros cerebrales superiores, para precisar las posibilidades del conocimiento perceptivo; requiere también lo que la psicología aporta acercá de la influencia quertiene la vida emocional, la memoria y la imaginación en la percepción misma. El aspecto perceptivo del conocimiento hay que entenderlo también tomando en consideración lo que la física nos indica sobre las características físicas del mundo de los objetos para precisar en qué medida la percepción es resultante del estímulo físico, y en qué medida lo es de la constitución anatómica y fisiológica de los sentidos. La ciencia nos enseña entonces, cuáles son las posibilidades de nuestro conocimiento y, aún más, si estudia el conocimiento sensorial en otras especies de seres vivos, pues, al meditar sobre sus limitaciones y posibilidades del conocimiento sensorial nos inclina a meditar sobre las posibilidades del conocimiento sensorial en el hombre mismo, y cómo su propia representación de la naturaleza se halla condicionada por la constitución de los sentidos. Por otra parte ¿cómo la teoría del conocimiento puede desconocer lo que aporta la teoría del aprendizaje? Esta nos indica los variados factores psicológicos que llevan a un conocimiento o nos desvían de él. Los fundamentos de las ciencias naturales y psicológicas, conjuntamente con lo que se deriva 
del conocimiento humano, en qué medida nuestro conocimiento es el reflejo de las condiciones psicosociales y biológicas, al mismo tiempo que nos indica sobre qué bases ha de partir una crítica del conocimiento, sobre qué fundamentos supera sus limitaciones biopsicosociales, y en qué finalmente debe reposar el verdadero conocimiento, para lo cual debe eliminarse todos los factores subjetivos y las restricciones de las perspectivas únicamente sociales. La teoría de los factores biológicos del conocimiento, la teoría del aprendizaje y la sociología del conocimiento, en tanto que estudian las condiciones en que se desarrolla el conocimiento, en tanto que permiten sopesar las condiciones en que se llevan a cabo, permiten destacar los factores subjetivos, dejando así abierto el camino para la comprensión más real de un conocimiento verdadero.

La teoría del conocimiento debe considerar las indagaciones llevadas a cabo por la psicología, especialmente en el terreno de la psicología del aprendizaje, pues ésta última tiene como propósito analizar el proceso del conocimiento, para lo cual estudia los factores que permiten desenvolver todas las fases cognoscitivas. ¿Qué posibilidades tiene la mente humana en el conocimiento $\mathrm{y}$ en qué se basan sus atributos psicológicos? ¿Qué posee su naturaleza y cuál ha sido su origen en las remotas condiciones vitales de la existencia y que de algún modo comparte el hombre con las diversas especies animales? Las llamadas categorías del conocimiento, ¿dependen exclusivamente de un atributo esencial del espíritu humano, o son adquisiciones que el individuo acumula desde la época de la infancia, como bien lo describe la psicología del desarfollo, 0 son adquisiciones también de la especie humanco efectuadais edi sundesariollo, como puede constatarse a través de la psicología social comparada? Las formas de conocimiento no pueden ser estudiadas sin tomar en cuenta las ciencias psicológicas en lo que indaguen sobre el origen o aparición de las llamadas categorías del conocimiento. Una reflexión filosófica, teniendo en cuenta los resultados de las ciencias psicológicas, permite ver desde un ángulo fundamentalmente distinto las llamadas categorías del entendimiento, que tanto influenciaron en los filósofos que se dedicaron a las teorías del conocimiento, cuando consideraron que las categorías mencionadas no eran sino formas del entendimiento puro o del espíritu. Las ciencias psicológicas al precisar qué formas fundamentales del conocimiento han sido adquisiciones del hombre en su desarrollo individual o de la especie en su desarrollo natural y cultural, permite establecer una nueva base en lo referente a las categorías del conocimiento. El otro gran problema de la teoría del conocimiento, a saber, la relación que hay entre el concepto y la realidad, es también ayudado en su solución por la ciencia, puesto que la solución solamente podrá alcanzarse, cuando se establezca si hay o 
no hay dependencia de las categorías del conocimiento de la realidad objetiva ajena al espíritu mismo, y que por haberse desarrollado al contacto con la naturaleza, hace factible el conocimiento de la naturaleza misma. De lo contrario, si quedase definitivamente demostrado que las categorías del conocimiento son el producto exclusivo del espíritu, que no se puede establecer vinculación alguna entre él y la naturaleza, entonces tampoco habría adecuación alguna entre lo que se llamaría conocimiento y realidad objetiva. Pero las ciencias psicológicas permiten encontrar una tercera posibilidad, que consiste en que el proceso del conocimiento humano se desenvuelve al contacto con la naturaleza o el mundo objetivo, pero también cuando el espíritu humano juega con las formas de conocimiento que ha adquirido y las lleva a una altura que parece ser esencialmente distinta a su forma natural. Sobre esto último cabría preguntarse: ¿es esto propiamente conocimiento, es esto o que ha llevado a algunos filósofos a situar el problema del conocimiento en un terreno idealista? De todos modos, la misma ciencia debe ayudar a resolver cómo ha sido posible esta transformación, como el conocimiento que tiene origen al contacto con la naturaleza, devenga en un conocimiento que parece ser ajeno a ella. La ciencia ha de ayudar pues a resolver qué relación hay entre categorías del conocimiento y naturaleza o mundo objetivo, y qué relación hay entre el concepto y ese mismo mundo objetivo. En cuanto a la lógica, su vinculación con la ciencia se establece de manera muy especial en la metodología porque los principios que rigen a esta última, dependerán de los planteamientos que las diversas ciencias hagan respecto a sus diversos objetos de estudio. En verdad, la metodología es esenciamente una filosofía que deriva de cada una de las ciencias, los principiosl metodológicos. La lógica general, en su forma de lógica simbólica o lógica matemática, ha podido estructurarse por su vinculación con las ciencias matemáticas, constituyéndose así en la lógica matemática.

Las diversas disciplinas filosóficas están pues íntimamente ligadas a la ciencia y de aquí que en la filosofía contemporánea no sea dable hablar de una filosofía verdadera al margen de la ciencia. La filosofía se relaciona con las ciencias mismas, con los principios que éstas obtienen al contacto con el mundo de los fenómenos de la naturaleza. Toda filosofía en algún momento ha de confrontar sus conclusiones con lo establecido en las ciencias mismas.

La filosofía, en cuanto a disciplina profundamente vinculada con la teoría de la ciencia, en la medida que la una y la otra no han de estar en oposición, en tanto que alguna de ellas constituye un aspecto de la realidad objetiva, lleva a la cuestión de si hary una vinculación de dependencia de la filosofía con respecto a la ciencia, o inversamente, de si la una y la otra mantienen sus áreas independientes. De los párrafos anteriores se desprende la imposibilidad de una completa independencia debido a que la filo- 
sofía desentraña las características universales de las cosas, y las ciencias las características particulares, pero que bajo ningún aspecto han de hallarse en contraposición. Mas esto último deja abierta todavía la posibilidad de que no obstante su compenetración esencial, en cuanto revelan la realidad, la filosofía no se halla sujeta a la ciencia, ni la ciencia a la filosofía. Como es conocido, la filosofía, antes de la aparición de la ciencia, fue la única disciplina reinante como expresión del anhelo de conocimiento en el hombre. Era una disciplina eminentemente especulativa, en el sentido que sobre la base de las primeras impresiones recogidas del mundo, el hombre añadía su meditación, la cual iba acompañada de un rico contenido emocional, sus creencias retrasmitidas en su medio cultural y el poder lógico de su pensamiento individual. En los inicios de la ciencia, la filosofía desenvuelta bajo una perspectiva especulativa, aún ha mantenido a la ciencia sujeta a su cuidado protector, de modo tal, que la filosofía proyectaba aún en las ciencias su perspectiva especulativa, como lo observamos en los filósofos presocráticos, quienes al amparo de algunas aún muy escasas observaciones de la naturaleza, deducían, ayudados por la lógica de su pensamiento, conclusiones sobre la estructura de la naturaleza La actitud especulativa, tanto en las cuestiones por antonomasia filosóficas como en el área propiamente científica, se manifiesta muy particularmente en el filósofo. La especulación filosófica surge en todas las épocas en que la ciencia se manifiesta rúdimentariamente, como sucedió en la Edad Media, y en todas las épocas, cuando el filósofo descuida el cultivo de la ciencia. Con tel cadvenimiento de la actitud científica, la recolección de los datos el establecimiento de leyes sobre la naturaleza, con su exigencia de una ciudadosa y minuciosa observación y experimentación, y con el creciente incremento de los aportes de la ciencia, logra ésta última independizarse de la filosofía y descuida las consideraciones filosóficas. La ciencia de nuestra época, con su copiosísimo acervo de conocimientos y con la confianza en sus propios métodos ha logrado, en principio, independizarse de la filosofía y contraponiéndose a ésta última, desdeñar sus vinculaciones de origen. El desarrollo de la ciencia ha alcanzado tal magnitud que le ha permitido independizarse de la filosofía, y como consecuencia paradójica, aparentemente, hacer a la filosofía dependiente de la ciencia misma. En efecto, la filosofía de la ciencia en la actualidad se consagra al análisis de los principios de las ciencias y ya no es la ciencia, como fue en sus inicios, la que se esfuerza en analizar los principios filosóficos para ajustarse a ellos, pues es ahora la filosofía que trata de configurarse conforme a la teoría de la ciencia, y se limita a su análisis lógico. Desde otra perspectiva, debido al mismo acervo de la ciencia y a la orientación científica de muchos filósofos surge, al lado de la filosofía, una filosofía científica, la que considera que la 
actitud del filósofo debe equipararse a la del científico, en cuanto basan ambos sus concepciones en la auscultación de la naturaleza $y$ el hombre, pero se diferencian solamente por la universalidad o por la particularidad de las disciplinas. Así, considerada, la filosofía tiene que incorporar las particularidades de la ciencia para elaborar la universalidad de sus principios. Es así cómo la filosofía científica mantiene una profunda vinculación con la ciencia y tiene que recurrir y depender de las conclusiones de la ciencia. A esta dependencia de la filosofía con respecto a la ciencia se oponen los filósofos que sostienen que esto es restringir considerablemente el pensamiento filosófico, hacerlo servilmente seguidor de la ciencia, someterlo únicamente a los datos de la ciencia $y$, por ende, negar toda originalidad y creatividad al filósofo. La filosofía, entonces, ha de estar por encima de los datos inmediatos de la ciencia y ha de continuar siendo especulativa, lo cual no significa vana, inútil y estéril contribución de la filosofía y, más bien, un propósito de trascender a lo aportado por la ciencia y de actuar en un área de conocimientos a la cual la primera no tiene acceso. Así la filosofía especulativa implicaría una actividad creadora y fructífera del espíritu humano. Es indiscutible que la capacidad especulativa del hombre lo lleva a trascender los datos y las relaciones causales inmediatos, así como las leyes de las ciencias, que hasta un momento determinado se conocen dentro de un área de la ciencia. Quien plantea nuevas hipótesis en la ciencia, quien busca descubrir nuevas relaciones causales, está poniendo en uso su capacidad especulativa, con la particularidad de que, a partir de hechos conocidos detlacciendia busca encontrar nuevas relaciones a nuevos hechos o datos, lo gual finalmente lo llevaría nuevamente a establecer nuevas relaciones, leyes y causas dentro del área científica. La actividad especulativa del hombre de ciencia es como un puente entre los acontecimientos no conocidos, pero en todo momento sujetos en su verificación a la experiencia. La capacidad especulativa del científico es libre de toda traba, pero en lo que no es libre es en una posible independencia de los acontecimientos que son conocidos a través de la experiencia, esto es, su actividad especulativa, su liberación de lo inmediatamente conocido, debe tarde o temprano ser sometido a la verificación de la experiencia, a la comprobación por los hechos y acontecimientos. La especulación del filósofo tiene dos manifestaciones distintas a la del científico, pero que como actividad mental desenvuelve una misma potencialidad. La filosofía especulativa, en su afán o motivación fundamental de desentrañar los primeros principios de las costas y de ordenarlos de acuerdo a su diferenciación, se extraña de los acontecimientos concretos, en gran parte por la dificultad de recolectar todos los acontecimientos concretos para someterlos a un análisis y precisar si responden o no a los principios universales, y en partes porque la capacidad es- 
peculatvia del hombre, que en este momento actúa como filósofo, lo llevan a desdeñar los acontecimientos concretos, y a atribuir a su capacidad intelectual una validez por sí misma y a reposar en esa capacidad confiadamente. Nos parece disculpable que por la universalidad de los problemas tratados, no se pueda considerar la infinidad de acontecimientos concretos, pero sí nos parece un deber de la filosofía el desear que sus afirmaciones universales sean reveladas en el acontecimiento concreto y que el filósofo desee que tarde o temprano así sea, y que en el caso de que los acontecimientos no respondan a las enunciaciones universales de la filosofía, sean estas sometidas a una reconsideración. La verificación de las enunciaciones filosóficas puede tardar decenios, e inclusive siglos, y dependerá de la genialidad de los filósofos el haberse anticipado de ese modo a lo que posteriormente será comprobado, o de aceptar humildemente que, con el transcurrir de los decenios o de siglos, los acontecimientos concretos no confirmen sus predicciones. Mas, no nos parece disculpable que el filósofo desprecie los hechos concretos y crea que la filosofía se puede erigir encima de ellos. Esta última actitud está además, en contra del acontecimiento concreto que es la historia de la filosofía, la cual hace ver cómo muchos planteamientos han sido refutados por nuevos descubrimientos, no solámente filosóficos, sino muy particularmente por los descubrimientos científicos. Paralela a esta filosofía especulativa, hay otra, que tiene raíces distintas, que se basa en la consideración de que el mundo está integrado por fuerzas espirituales, como el alma, la divinidad y que, por ende, la fuerza espiritual que está inmersàa èn el mundō nō se-deja analizar por una actitud científico-materialista, y por consiguiente es inverificable y la razón especulativar del filosofo debel sersIa única que lleve la responsabilidad de la disciplina. Aun cuando esta fe es la razón para descubrir las fuerzas espirituales del mundo y su apartamiento de los acontecimientos concretos es más disculpable que cuando se trata de los acontecimientos físicos, porque la razón humana, es la única susceptible de ponerse en comunicación con las fuerzas espirituales, nos parece que si así fuese el universo — cisun. to que ahora no está en discusión - sin embargo, aún esta filosofía espiritualista que desea apoyarse en la razón especulativa, anda errada en considerar de que por tratarse de fuerzas espirituales, los acontecimientos concretos no han de ser tomados en consideración. En efecto, los hechos concretos revelan las fuerzas físicas del mundo, pero no solamente estas fuerzas físicas sino también han de revelar las fuerzas espirituales. Se puede ser materialista o espiritualista, pero estas posiciones filosóficas no se hallan en contraposición con el hecho de que los acontecimientos del mundo, los acontecimientos concretos, revelan o las fuerzas materiales, o las fuerzas espirituales, o ambas. De aquí que toda filosofía, la ma- 
terialista y la espiritualista, debe someter sus enunciados, tarde o temprano, a su verificación por los acontecimientos concretos.

La filosofía se encuentra en relación con los diversos campos de la ciencia. Así, el concepto de magnitud, y que es motivo de estudio de las ciencias matemáticas, no puede apartarse de lo que las ciencias matemáticas vayan aportando a la elaboración y modificación de los criterios referentes al concepto de magnitud. Tratándose del estudio de la esencia de los fenómenos físicos, la filosofía ha de considerar necesariamente los descubrimientos de las ciencias físicas sobre la constitución de dichos fenómenos. ¿Cómo podría la filosofía fundamentar sus principios sin estimar lo que las ciencias biológicas esclarezcan sobre la naturaleza de la vida, que es un aspecto esencial de la filosofía? ¿Cómo el estudio de la mente y del psiquismo en general, asunto primordial de la filosofía de todos los tiempos, podrían llevarse a cabo sin reflexionar sobre los resultados a que ha llegado la psicología científica? En cuanto a la esencia de lo social, la filosofía de las ciencias sociales, incluyendo a la filosofía de la historia, no puede ser ajena a lo que las ciencias sociales e históricas digan, a lo que hubiesen llegado en sus indagaciones. La filosofía para determinar cuál es la esencia de la magnitud, de lo físico, de lo biológico, de lo psíquico y de lo social, tiene que considerar los resultados a los que hayan llegado las respectivas ciencias. Tales esencias constituyen una de las regiones del ser y por lo tanto la cuestión básica de la filosofía: ¿qué es el ser?, no puede encontrar una respuesta adecuada sino solamente teniendo presente las modalidades de] ser en su forma propia de manifestarse,-según a la región a la que pertenezca. Es así que la teoría del ser ha de tomar en cuenta la ciencia misma, laj apliedilidadebinooalvsers de la categoría de movimiento, de espacialidad o temporabilidad, así como la cuestión de si el determinismo rige o no en el ser, tiene que tratarse en la ciencia, para precisarse si actúan en una de las regiones del ser, en todas o en ninguna. Igualmente, ¿la categoría de materia es aplicable únicamente a los fenómenos físicos o puede ampliarse su aplicación al psiquismo, o acaso la categoría de materia no es aplicable ni aun a los fenómenos físicos? Sin la ciencia misma no puede darse una respuesta adecuada a estos problemas que la filosofía incesantemente ha intentado responder al hacerse la pregunta sobre lo que es el ser.

Después de establecer la relación entre la filosofía genera] y la ciencia misma, quedan dos posiciones por definirse. La primera desligando a la filosofía de toda dependencia con la ciencia, sosteniendo que son dos campos totalmente distintos y que vincular la filosofía con la ciencia sería quitarle injustificadamente su jerarquía, reduciéndola en última instancia a los datos empíricos. Se sostiene de que en definitiva están completamente separadas porque cada cual tiene su mundo propio, tanto por el método como 
por el objeto de investigación. Esta posición afirma que la misma ciencia no puede apoyarse únicamente sobre la ciencia porque en toda ciencia hay principios, ideas o conceptos que no son derivados de la experiencia, sino que más bien la ciencia es posible porque se apoya en concepciones que a manera de presupuestos, en sí independientes de toda experiencia; y más bien, su valor radica en que precisamente son utilizados para ordenar los datos empíricos, y que un análisis de esos presupuestos revela que intervienen en las concepciones científicas esencialmente como una elaboración espiritual, que a manera de hipótesis se van sustituyendo y sucediendo en la historia de la ciencia. No sería entonces posible, de acuerdo a esta posición, una ciencia que no tuviera presente esos presupuestos esencialmete de origen espiritual o sea presupuestos de la mente que inevitablemente intervendrán en toda elabora ción de la ciencia. La filosofía tendría, más bien, de acuerdo a esta posición, que estudiar estos criterios fundamentales que posibilitan el pensamiento científico, y que hacen posible la ciencia misma. Por ejemplo, la misma categoría de causalidad que ha regido el desarrollo de la ciencia, podría ser solamente un presupuesto, como lo intentan demostrar en la ciencia actual, al hacer patente el que los elementos de la materia no se rigen por leyes causales y, sin embargo, la categoría de causalidad ha estado siempre en el pensamiento científico. El mismo concepto de materia parece ser otro presupuesto en el cual los hombres han creído por siglos, en tanto que hoy en día se puede alegar que es la energía lo fundamental y que la materia ha sido solamente una suposición de la mente. El análisis que puede llevar a cabo da filosofía permitiría desentrañar muchos de estos presupuestos en la ciencia. Por consiguiente, todo intentogde vincular la filosofice con la ciencia, en tanto que datos proporcionados por el mundo exterior, está en lo fundamental destinado a convertirse en un imposible, porque la ciencia misma se desarrolla con presupuestos ajenos al mundo exterior. Estos presupuestos son pues metafísicos y no físicos. La metafísica habría de mantenerse siempre como una disciplina completamente independiente y soberana y antes de explicarse por la ciencia, ella misma explica a la ciencia. En el fondo de esta posición, hay un mundo irreductible a los fenómenos físicos y que justifica perennemente una disciplina filosófica por excelencia, llamada metafísica. El campo de la filosofía y el campo de la ciencia son irreductibles porque en definitiva, el mundo de los fenómenos físicos y el mundo de lo espiritual son ellos mismos irreductibles. De lo anteriormente expuesto se puede colegir que si la filosofía esté vinculada o no con la ciencia, dependerá en última instancia de la solución que se dé el problema antagónico del materialismo y del idealismo. O bien la filosofía general tendría como destino el fundamentarse en la ciencia misma, en cuanto ésta proporciona conocimientos obtenidos únicamente en el mundo exterior de los fe- 
nómenos físicos, y en este caso, será verdadera la posición asumida por el materialismo; o bien la filosofía es finalmente independiente de la ciencia, en el sentido de lo dicho anteriormente, en cuanto tiene presupuestos que no provienen de los fenómenos físicos, y en este caso será verdadera la posición asumida por el idealismo. En ambos casos habrá que compararlas.

Al incursionar en las cuestiones fundamentales de la filosofía de la ciencia y tratarlas con detención hay que distinguir previamente entre filosofía y teoría científica. De primera intención parecen ser lo mismo, como lo comprueba el hecho de que el estudio de la filosofía tiene que considerar los conocimientos que se hallan en los estudios propiamente científicos. Por otro lado, esta misma confusión aumenta porque algunos teóricos de la ciencia usan indebidamente la denominación de filosofía para referirse a la teoría científica. Sin embargo, tratemos de hacer una distinción al resaltar que la filosofía tiene por objetivo el estudio de las categorías fundamentales que rigen en el campo de cada una de las disciplinas científicas, tanto al determinar cuáles son éstas, como al establecer la correlación entre ellas mismas. En cambio, la teoría científica es en parte todo conocimiento que proviene del intento de deslindar conceptos sin recurrir a los datos concretos que la misma ciencia proporciona de inmediato, y por lo tanto su intento se lleva a cabo dentro de concepciones, hipótesis y suposiciones; en parte también, la teoría científica contiene los principios, o leyes, o asuntos más trascendentes, que se hallan en cada una de las disciplinas científicas. Hay sin embargo un modo de abordar el problema científico porpla teoría científica que se superpone con la filosofía, cuando el científico se plantea la cuestión de cuál sea en definitiva la naturalezaddel fenómeno 8 acontecimiento que es el objeto de su determinada disciplina científica: ¿Cuál es, por ejemplo, la naturaleza originaria de los fenómenos físicos o biológicos, o del acontecer histórico? En ește planteamiento, el científico se aboca a un problema que es de interés primordial a la filosofía, a saber, cuál es la esencia de las cosas, planteamiento que trata de resolver con la categoría fundamental de cada una de las ciencias. Esta categoría fundamental es el punto de enlace entre teoría científica y filosofía, el punto en el que las dos son una misma disciplina. Aunque muchas veces sea difícil distinguir en un mismo tratadista de que si lo que aborda es teoría científica o filosofía, sin embargo, esta última es la que tiene como objeto de estudio las categorías fundamentales de cada una de las ciencias, y llámese a este estudio teoría científica o filosofía no es asunto de importancia, sino el que la filosofía se refiere al estudio de las mencionadas categorías. Pero la filosofía se distingue de la teoría científica, en que la primera tiene un programa más ambicioso, porque, después de estudiar las categorías de cada una de las ciencias, compara a éstas entre sí con el propósito de encontrar la unidad 
que haya entre ellas y llegar a concluir cuáles sean los principios que rigen a todas las cosas, sin excepción alguna. La finalidad de la filosofía de todos los tiempos es hallar una respuesta de si el universo se rige por principios unitarios y en caso de que no los hubiera, cuál es la base de la separación. La filosofía pues, al comparar las categorías de cada una de las ciencias, debe de responder a esa cuestión, por lo cual la filosofía deviene en teoría general del ser.

De lo anteriormente expuesto, podemos intentar definir la filosofía como disciplina que estudia las categorías de cada una de las ciencias, así como las categorías que son universales a todas las ciencias, y cuál es la distinción esencial entre las propias de cada ciencia. Además de llevar a un esclarecimiento por intermedio de la crítica científica el problema tradicional de la filosofía, el problema del ser, lleva también a un esclarecimiento los otros dos problemas tradicionales de la filosofía, el problema del conocimiento y el problema del valor, que en última instancia se fundamentan en el ser de las cosas.

La filosofía, que es posiblemente la más antigua disciplina con que la humanidad cuenta, ha pasado sin embargo por innumerables vicisitudes, debido a que el campo que la filosofía consideraba como suyo, fue siempre disputado por otras disciplinas que alegaron tener jurisdicción en el terfitorio en el que la filosofía se había establecido. Desde la antigüedad tanto las ciencias físicas y matemáticas, así como la psicología y las ciencias sociales fueron abordadas por los filósofos e incorporadas dentro de su sistema. En verdad, cualquier asșpecto del saber humano fue considerado como parte de la filosofía. Solo poco a poco en el transcurso de los siglos, fueron despréndiéndosecale la filosofia spropiamente dicha, diversos aspectos del saber que con el tiempo se han constituido en disciplinas científicas e independientes de la filosofía.

A pesar de este proceso de diferenciación que ha tardado varios siglos, hoy en día seguimos encontrando la pertinaz insistencia de los filósofos de recoger en los fundamentos de cada una de las ciencias, material para elaborar sus principios filosóficos. Y no sólo esto, sino que muchos filósofos son especialistas en alguna disciplina científica y su filosofía versa muy particularmente sobre principios filosóficos que pretenden ser la explicación última de dicha disciplina científica. Por otro lado, muchos hombres de ciencia revelan su interés por una adecuada versación filosófica y ellos también, muy particularmente, se interesan por la filosofía que se refiere al campo científico a que ellos se dedican. Como resultado de esto, al dedicarse tanto filósofos como científicos a asuntos correlativos de una misma esfera del saber, es muchísimas veces muy difícil decir - si no imposible- si lo que se enuncia es un principio filosófico o científico. Por eso constatamos que hoy en día, como hace muchos siglos, la filosofía y la ciencia se hallan y 
disputan en un mismo terreno. Estos hechos, tanto la tendencia de las ciencias a separarse de la filosofía como la tendencia a unirse nuevamente en un determinado aspecto del saber, de primera intención invitan a reflexionar cuál sea la relación de la filosofía con la ciencia y de si hay un campo genuinamente filosófico.

El hecho histórico de la relación de la filosofía con la ciencia nos permite ver que la filosofía y la ciencia asumen una actitud que es común a ambas, esto es, que tratan de abordar un mismo objeto del conocimiento. Por eso, en la filosofía de todos los tiempos, el filósofo siempre ha incluido dentro de sus estudios algún campo de la investigación científica. Sin embargo, debe haber alguna razón por la cual las ciencias han tratado de independizarse de la filosofía. En primer lugar, esta razón parece deberse en que a medida que los investigadores de las diversas ciencias fueron acumulando más y más material concreto, se hizó mayormente necesaria la separación de la ciencia de la filosofía, en cuanto que la ciencia se interesa por principios y leyes más concretas, en tanto que la filosofía busca principios universales. Ahora bien, en la época en que los datos científicos fueron relativamente escasos, el filósofo podría incorporar y elaborar dentro de su sistema dichos datos y ser, por ende, al mismo tiempo un científico en una o más disciplinas. Porque además, lo limitado del material científico acumulado le permitía más fácilmente elaborar dichos datos concretos bajo principios universales. Como resultado de esto, el filósofo al mismo tiempo que tal, era también un científico teórico. A medida que las ciencias han ido aumentando más y más su caudal, el filósofo ha circunsćtito suseaspiraciones científicas y en la actualidad por eso, que al mismo tiempo que filósofo, es muchas veces teórico en alguna ciencia determinada.

$\mathrm{Si}$ se tiene en cuenta también que la ciencia posee dos grados en cuanto a la generalización se refiere: un nivel de datos concretos y de leyes circunscritas y limitadas, y otro nivel de mayor alcance en su universalidad, esto es, como teoría científica, se comprende que debido a este segundo nivel, el filósofo y el científico se hallan en una zona de contacto.

Constatamos entonces que en la propensión del científico a situarse en un campo teórico y en la tendencia del filósofo a ser un científico teórico - hechos ambos repetidos incesantemente en la historia de la cultura favorece el que la filosofía y la ciencia tengan un objeto común. Pero entonces, ¿en qué han de distinguirse la ciencia y la filosofía? La teoría de la ciencia obedece a la necesidad de encontrar principios universales en una determinada disciplina científica. Pero el filósofo aspira a encontrar en dichos principios un criterio aún más universal con el cual explicar el sentido primero de los fenómenos en un campo de la ciencia. Cierto es que no puede alcanzar un criterio válido si no se basa en los postulados teóricos de una ciencia. Pero el filósofo no se afana únicamente 
en captar el principio general, que explica todos los fenómenos de una ciencia, sino que aún más, compara categorías de las diversas ciencias, para hallar cuál sea el principio común a todas ellas, y que sea el principio universal que rige las manifestaciones de las cosas y que se constata en el estudio de diversos campos científicos.

Al buscar este principio universal que rige las diversas manifestaciones de los hechos, la filosofía va elaborando paulatinamente una teoría que se refiere al principio de todos los seres en general. Desde este momento, la filosofía es teoría del ser, pero la teoría del ser es un principio más universal aún, que los que se hallan en diversas disciplinas científicas. Por eso, la filosofía en forma gradual se va poniendo en contacto con la teoría científica e inversamente, la ciencia va situándose cada vez, más cerca del campo de la abstracción filosófica.

La filosofía, elaborada ya sea por el que se llama filósofo o por el científico - es la genuina expresión de la necesidad de hallar las principios universales de la naturaleza. En este sentido, hay unidad entre filosofía y ciencia y sólo se diferencian por su mayor o menor universalidad.

Es cierto que la filosofía no siempre procede de esta manera, esto es, basándose en los postulados de las teorías científicas para elaborar una teoría del ser, pues muchas veces el filósofo elabora sus principios ontológicos sin un estudio, de la teoría científica. Esto se debe a veces a la inmensa capacidad abstractiva de algunos pensadores que les permite intuir ciertos principios universales. Pero otras veces; del filósofo se revela con mayor intensidad, actitudes de su personalidad, su medio sociall zela lualtural que habledibido. Es sin embargo significativo que los filósofos pretendan que sus principios sean válidos para todas las ciencias y que, por otra parte, ellos mismos se hayan esmerado en cultivar las disciplinas científicas, y que de algún modo u otro, pretendan validar sus "intuiciones" en las ciencias mismas. Porque después de todo, presienten que la filosofía y la ciencia deben colaborar.

El filósofo debe aspirar a elaborar la teoría del ser después de un detenido examen de la teoría científica. Esto no quiere decir que el filósofo tenga como misión resumir en principios universales lo que es común a las diversas teorías científicas, sino que el filósofo debe preservar cautelosamente sus intuiciones y elaborar su sistema filosófico sólo después de un detenido estudio de la teoría científica y elaborar la teoría del ser de modo crítico y teniendo siempre en mente esas teorías. La fortuna de la filosofía dependerá de que los hombres con verdadero sentido filosófico se basen en hechos dados con la mayor objetividad posible por la teoría de las ciencias. Es cierto que es difícil para los hombres desprenderse de su naturaleza personal o de la influencia de su medio am- 
biente, pero precisamente mientras más asuman una actitud basada en la ciencia, más se liberarán de sus propias limitaciones. La filosofía es pues el estudio del ser, esto es, el estudio de los principios de máxima universalidad en los procesos de la naturaleza.

Ahora bien, la teoría del ser, aun cuando aspire a los primeros principios del ser, debe tener siempre en cuenta que no es dable alcanzarlos sino paulatinamente, tanto individual como históricamente. En este sentido los filósofos deben de estar alertas a que los principios ontológicos estén sometidos a continua crítica, para así alcanzar cada vez mejor los verdaderos principios filosóficos. Al igual que la ciencia, la filosofía ha de someterse a reajustes continuos en lo referente a sus principios. De esta manera la filosofía ha de expresar con mayor madurez la validez de sus principios. Porque sólo así, se podrá alcanzar el ideal de que los nuevos principios filosóficos no invalidan completamente los anteriores, sino que, más bien, los integren desde un plano superior, en forma semejante a lo que sucede en el campo de la ciencia.

Desafortunadamente para la filosofía y la cultura en general, muchos filósofos no siempre procedieron con la cautela necesaria y, más bien, elaboraron sistemas que los dieron por absolutos $\mathrm{y}$ eternos. Pretensión que fúe invalidada por otros pensadores, dando por resultado el fenómeno - que se ha dado únicamente en la historia de la filosofía- del derrocamiento total de los sistemas filosóficos, y que ha contribuido tantas veces al descrédito de la filosofía. La filosofía ha de estar continuamente alerta de la necesidad de superar sus principios y de remozarse continuamente con la ciencia. Es encomiable que los filósofos aspiren a la máxima universalidad o primeros principios, pero que no crean que siempre la han alcanzado. IEscconveniente quie los filósofos no "hipostasien" las naturales y necesarias tendencias de alcanzar la universalidad.

Las leyes de la filosofía expresan, pues, la modalidad de los seres, los principios generales de su comportamiento. Las leyes de la filosofía han de reflejar las características del ser y por lo tanto son válidas para las diversas manifestaciones del ser mismo, desde la esfera meramente física a la consciente. Pero cabe averiguar si las leyes de la filosofía no sufren alguna modificación en la esfera del ser en que se apliquen y, si así fuese el caso, al lado de las leyes generales de la filosofía, hay leyes particulares filosóficas, que especifican en cada esfera del ser, características que no se encuentran en las demás. La filosofía habrá de investigar, entonces, las leyes generales del ser y las leyes particulares específicas dentro de cada ámbito del ser.

Las leyes generales de la filosofía como se refieren a todos los seres, pueden investigarse en cualquier manifestación del ser y por lo tanto podrán descubrirse en cualesquiera de sus esferas. En cambio, las leyes filosóficas particulares se descubrirían en al- 
guna de las ciencias en particular y en la observación del comportamiento del ser en una esfera determinada. Es evidente que las leyes filosóficas generales no se descubren exclusivamente en alguna de las ciencias, o en una esfera determinada, pues se descubren en todas las ciencias y ámbitos del ser. Las leyes filosóficas particulares pueden confundirse con la teoría científica particular. ¿Hay alguna diferencia entre las leyes filosóficas particulares y la teoría científica en particular? En verdad, no existe todavía una teoría científica en particular, porque dentro de cada ciencia hay muchos aspectos teóricos que mantienen una relativa independencia entre sí. Por ejemplo, en la física, las leyes de la mecánica, la teoría del electromagnetismo, la teoría atómica, y otras, constituyen diversos planteamientos teóricos que reflejan diversas manifestaciones del mundo material, y que la ciencia misma las mantiene con una relativa independencia. En cambio las leyes filosóficas de una ciencia en particular debería intentar interrelacionar y derivar los diversos planteamientos teóricos de ciertos principios generales que se obtienen al estudiar en toda su amplitud el ser material. Es cierto que esta última tarea también podrá lograrla el científico teórico, pero sea el filósofo o el científico el que lo logre, éste será un paso considerable para conocer las características del ser material, y ha de enriquecer profundamente el conocimiento que lleve a un mayor conocimiento del ser en general. ¿Llegarán a integrarse las leyes filosóficas particulares con la teoría científica en particular? Es muy probable, pero siempre habrá que distinguir, las teorías cientificas en particular de las leyes filosóficas particulares.i Estas últimas no son sino una mayor generalización de lo anterior, con 10 cual se establece un estrecho contacto entre la filosblíag Q Placteionédicientífieaso"

Solamente vinculada a una observación rigurosa del mundo y estrechamente relacionada con la ciencia, es posible que la filosofía se desarrolle sistemáticamente a lo largo de su historia, y contribuya a la transformación de la naturaleza y de la sociedad. Corresponde entonces a los filósofos influir en la solución de las cuestiones principales del hombre, de su educación y en la renovación de las teorías científicas de cualquier índole. De este modo, sus principios, directa o indirectamente, son una herramienta en el desenvolvimiento de la cultura y del hombre.

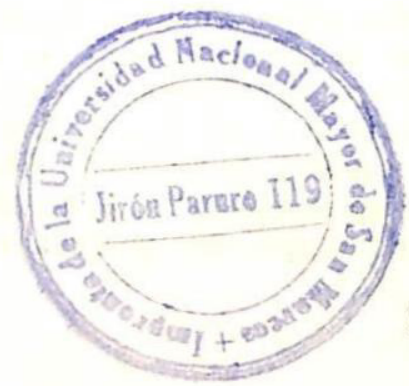

